\title{
CAMP signaling in cortisol-producing adrenal adenoma
}

\author{
Davide Calebiro ${ }^{1,2}$, Guido Di Dalmazi ${ }^{3}$, Kerstin Bathon ${ }^{1,2}$, Cristina L Ronchi ${ }^{4,5}$ \\ and Felix Beuschlein ${ }^{3}$ \\ ${ }^{1}$ Institute of Pharmacology and Toxicology, University of Würzburg, Versbacher Str. 9, 97078 Würzburg, Germany \\ ${ }^{2}$ Rudolf Virchow Center, Josef-Schneider-Str. 2, 97080 Würzburg, Germany, ${ }^{3}$ Medizinische Klinik und Poliklinik IV, \\ Ludwig-Maximilians-Universität München, Ziemssenstraße 1, 80336 München, Germany, ${ }^{4}$ Department of Medicine \\ I, Endocrine and Diabetes Unit, University Hospital, University of Würzburg, Oberdürrbacher Str. 6, 97080 \\ Würzburg, Germany, ${ }^{5}$ Comprehensive Cancer Center Mainfranken, University of Würzburg, Josef-Schneider-Str. 6 , \\ 97080 Würzburg, Germany
}

Correspondence should be addressed to D Calebiro

Email

davide.calebiro@ toxi.uni-wuerzburg.de

\begin{abstract}
The cAMP signaling pathway is one of the major players in the regulation of growth and hormonal secretion in adrenocortical cells. Although its role in the pathogenesis of adrenocortical hyperplasia associated with Cushing's syndrome has been clarified, a clear involvement of the CAMP signaling pathway and of one of its major downstream effectors, the protein kinase A (PKA), in sporadic adrenocortical adenomas remained elusive until recently. During the last year, a report by our group and three additional independent groups showed that somatic mutations of PRKACA, the gene coding for the catalytic subunit $\alpha$ of PKA, are a common genetic alteration in patients with Cushing's syndrome due to adrenal adenomas, occurring in $35-65 \%$ of the patients. In vitro studies revealed that those mutations are able to disrupt the association between catalytic and regulatory subunits of PKA, leading to a CAMP-independent activity of the enzyme. Despite somatic PRKACA mutations being a common finding in patients with clinically manifest Cushing's syndrome, the pathogenesis of adrenocortical adenomas associated with subclinical hypercortisolism seems to rely on a different molecular background. In this review, the role of CAMP/PKA signaling in the regulation of adrenocortical cell function and its alterations in cortisolproducing adrenocortical adenomas will be summarized, with particular focus on recent developments.
\end{abstract}

\section{Introduction}

The cAMP signaling pathway plays a fundamental role in regulation of metabolism, cell proliferation, differentiation, and apoptosis in endocrine tissues (1). A major effector of cAMP is protein kinase A (PKA), which phosphorylates a number of substrates, including cytosolic and nuclear targets, most notably transcription factors of the CREB/ATF family (2). Activation of the cAMP pathway causes both increased function and replication of several endocrine cells, including those of the adrenal cortex (2). Thus, alterations of this pathway have been found in different endocrine diseases. Lossof-function mutations are responsible for syndromes of

Invited Author's profile

Davide Calebiro is an endocrinologist and a receptor scientist. Since 2009, he is Group Leader at the Bio-Imaging Center/Rudolf Virchow Center and Institute of Pharmacology of the University of Würzburg, Germany. His group utilizes optical methods such as fluorescence resonance energy transfer and single-molecule microscopy to investigate the spatiotemporal dynamics of receptor signaling in living cells. His major recent contributions include the discovery of GPCR signaling in the endosomal compartment and the identification of mutations in the catalytic subunit of protein kinase A (PKA) as a cause of adrenal Cushing's syndrome.

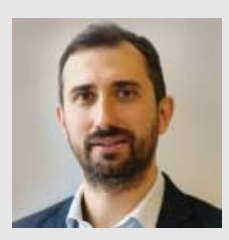

(C) 2015 European Society of Endocrinology Printed in Great Britain Published by Bioscientifica Ltd.
This article is adapted from work presented at IMPROCUSH-1, 12-14 October 2014. The meeting was supported by the European Science Foundation, Deutsche Forschungsgemeinschaft, Carl Friedrich von Siemens Stiftung, European Neuroendo-

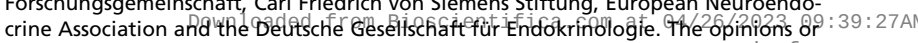
views expressed in this article are those of the authors, and do not necessarily reflecte access the opinions or recommendations of the supporters of the symposium. 
hormone resistance like pseudohypoparathyroidism (3) or thyrotropin (TSH) resistance (4). Conversely, mutations leading to constitutive activation of this pathway lead to tumor development and hormone excess, as in the case of thyroid adenomas or growth hormone $(\mathrm{GH})$-secreting pituitary adenomas $(5,6,7)$.

Under normal conditions, adrenocortical cells are under the tight control of the adrenocorticotropic hormone (ACTH), which signals via the melanocortin 2 receptor (MC2R), a G protein-coupled receptor (GPCR) expressed in high abundance on the surface of adrenocortical cells. Activation of the MC2R, which is coupled to the stimulatory $G_{s}$ protein, leads to an increase of the intracellular concentration of cAMP and activation of PKA, ultimately stimulating glucocorticoid production. Whereas the role of ACTH in stimulating the proliferation of adrenocortical cells remains a matter of investigation, in vitro data, animal models, and, most importantly, a number of human genetic defects clearly demonstrate the central role of the cAMP/PKA pathway in the pathophysiology of adrenal hyperplasia and hypercortisolism. In contrast to familial forms of adrenal Cushing's syndrome, the pathogenesis of the much more frequent cases of sporadic, unilateral cortisol-secreting adrenal adenomas had remained largely obscure. Recently, we and three additional independent groups have identified a high frequency (35-65\%) of somatic mutations affecting the catalytic alpha subunit of PKA (PRKACA) in cortisolsecreting adrenal adenomas $(8,9,10,11)$. In this review, we provide an overview on the role of cAMP/PKA in the control of adrenocortical cell function and its alterations in Cushing's syndrome, with a particular focus on recent developments.

\section{Clinical spectrum of adrenal Cushing's syndrome}

Endogenous hypercortisolism associated with unilateral adrenocortical adenomas is the most common form of ACTH-independent Cushing's syndrome, occurring in almost one-third of patients with overt Cushing's syndrome (12). The clinical picture of patients with Cushing's syndrome is characterized by severe comorbidities and adverse events, due to the effect of excessive cortisol production. Given that the glucocorticoid receptor is widely expressed in almost all tissues, the effects of cortisol hypersecretion inevitably involve many organ systems. The classic clinical picture of a patient affected by Cushing's syndrome is characterized by easy bruising, facial plethora, proximal muscle weakness, striae rubrae, and hirsutism
(Table 1) (13). In addition, hypertension is a very common feature of the syndrome, occurring in $80 \%$ of the patients, and is characterized by drug resistance in up to $17 \%$ of cases, as well as by loss of nocturnal dipping $(14,15,16)$. Alterations of glucose and lipid metabolism are also common findings in patients with Cushing's syndrome. All those comorbidities, together with the typical hypercoagulable state due to alterations of clotting factors (17), severely impair the cardiovascular profile of patients with Cushing's syndrome, leading to an increased incidence of cardiovascular events and mortality, if left untreated $(18,19)$. Considering that the cardio-metabolic impairment in those patients is often associated with an increased rate of severe infectious complications (20), an increased incidence of osteoporotic fractures, and psychiatric disorders (21), it is clear that patients with Cushing's syndrome are characterized by a life-threating disease that requires a precise causative diagnosis and a rapid therapeutic strategy. A comprehensive review on the complications of Cushing's syndrome and their treatment has been recently published elsewhere (19) and is beyond the scope of this review.

The term 'subclinical hypercortisolism' has been commonly used in the last years to define a condition of hypercortisolism, detected by hormonal alterations of the HPA axis, in patients without a clear phenotype recalling that of Cushing's syndrome. By definition, subclinical hypercortisolism is diagnosed in patients with incidentally

Table 1 Clinical presentation of Cushing's syndrome and subclinical hypercortisolism (adapted from reference (13)).

Cushing's syndrome
Specific signs
Easy bruising
Facial plethora
Proximal myopathy
Striae (red-purple, $>1 \mathrm{~cm}$ wide)
In children: weight gain with reduced growth velocity
Symptoms
Weight gain, changes in appetite
Depression, mood changes
Reduced concentration and memory
Insomnia, fatigue
Decreased libido
Oligomenorrhea
Recurrent infections
Less discriminatory signs and symptoms
Facial fullness, central obesity
Buffalo hump, supraclavicular fullness, acne, and hirsutism
Thin skin, poor wound healing
Peripheral edema
Subclinical hypercortisolism
Biochemical evidence of mild cortisol excess without specific
signs of Cushing's syndrome


discovered adrenal tumors. Therefore, in the last years, subclinical hypercortisolism has been used for patients who do not fulfill the criteria either for Cushing's syndrome or for non-secreting tumors. In the last decades, the study of subclinical hypercortisolism has gained more interest because of the increasing number of cases reported in a relevant fraction of patients with adrenal incidentalomas (up to 30\%) (22), which are discovered in a relatively large number of subjects (up to $4 \%$ in radiological series) (23).

The clinical picture of patients with subclinical hypercortisolism is characterized by several comorbidities such as hypertension, type 2 diabetes, and dyslipidemia (Table 1), but also by clinically relevant outcomes, mainly osteoporotic vertebral fractures, cardiovascular diseases, and related mortality. Several cross-sectional studies have highlighted that glucocorticoid-induced osteoporosis (GIO) and its related complications indeed occur also in patients with subclinical hypercortisolism $(24,25,26,27$, $28,29)$. Moreover, three recent retrospective studies showed a role for mild cortisol hypersecretion in the development of cardiovascular diseases in patients with subclinical hypercortisolism $(30,31)$. Indeed, the incidence of cardiovascular diseases was higher in those patients with respect to their non-secreting counterpart, and the increase in cortisol levels over time was independently associated with the risk of cardiovascular events. Similarly, the survival rate was lower in patients with subclinical hypercortisolism, when compared to non-secreting adrenocortical adenomas (31) and to the general population (32), due to an increased cardiovascular mortality and infectious complications.

In summary, while the clinical spectrum of adrenaldependent hypersecretion of cortisol is wide, it has become quite clear that in most instances adrenal hypercortisolism represents a relevant clinical problem.

\section{Role of CAMP/PKA signaling in adrenocortical cells}

The second messenger cAMP and its effector PKA are key regulators of virtually all cellular functions, such as growth and differentiation, and mediate the effects of several hormones and neurotransmitters that signal via GPCRs. The discovery of this pathway represented fundamental milestones in cell biology, which culminated with the assignment of three Nobel prizes: the first in 1971 to Earl Sutherland for the discovery of cAMP, the second in 1992 to Edmond Fischer and Edwin Krebs for the discovery of PKA, and the third in 1994 to Alfred Gilman and Martin Rodbell for the discovery of G proteins (33).
PKA is a prototypical serine/threonine kinase and a primary example of allosteric regulation (34). The PKA holoenzyme in its inactive form is a tetramer consisting of a dimer of two regulatory (R) and two catalytic (C) subunits (34). There are three known isoforms of $\mathrm{C}$ subunits $(\mathrm{C} \alpha, \mathrm{C} \beta, \mathrm{C} \gamma)$ and four of $\mathrm{R}$ subunits (RI $\alpha, \mathrm{RI} \beta$, RII $\alpha$, RII $\beta$ ), each coded by a separate gene (34). In addition to the $C$ subunits, the human protein kinase $X$ also can associate with the R subunits of PKA (35). The regulatory subunits form homo- or heterodimers via the docking and dimerization (D/D) domain $(34,36)$. This domain is also responsible for the binding of A kinase-anchoring proteins, which tether different PKA isoforms to specific subcellular strutures (34). In the inactive holoenzyme an inhibitory sequence derived from each $\mathrm{R}$ subunit occupies the active site cleft of the corresponding $\mathrm{C}$ subunit, behaving as a tethered substrate or pseudo-substrate and thus precluding the access of PKA substrates (34). Upon binding of two cAMP molecules to each $\mathrm{R}$ subunit, the $\mathrm{C}$ subunits are released from the holoenzyme and can phosphorylate their targets localized in the cytosol as well as in the nucleus (37). In adrenocortical cells, this leads to an acute stimulation of glucocorticoid synthesis as well as to a later, transcriptional induction of steroidogenic enzymes and genes involved in cell replication (38, 39) (Fig. 1).

\section{Genetic defect associated with adrenal Cushing's syndrome}

A number of genetic defects in the cAMP/PKA pathway have been associated with adrenal diseases (40). The first defect was identified in patients affected by the McCuneAlbright syndrome, characterized by bone fibrous dysplasia, café au-lait skin spots, and hypersecretion from different endocrine glands. These patients were found to carry mosaic, activating mutations in the gene coding for the $G \alpha_{s}$ protein (GNAS) (41). A minor fraction of McCune-Albright patients develop Cushing's syndrome due to adrenal hyperplasia (42). A second genetic defect involves the gene coding for the RI $\alpha$ subunit of PKA (PRKAR1A). PRKAR1A mutations are responsible for Carney complex, another multiple endocrine neoplasia syndrome, characterized by the presence of primary pigmented nodular adrenocortical disease, cutaneous and neuronal tumors, cardiac myxomas, as well as characteristic pigmented lesions of the skin and mucosae (43). These mutations cause a reduced expression of the RI $\alpha$ subunits or impair its association with $C$ subunits, thus leading to constitutive PKA activation (44). More recently, 


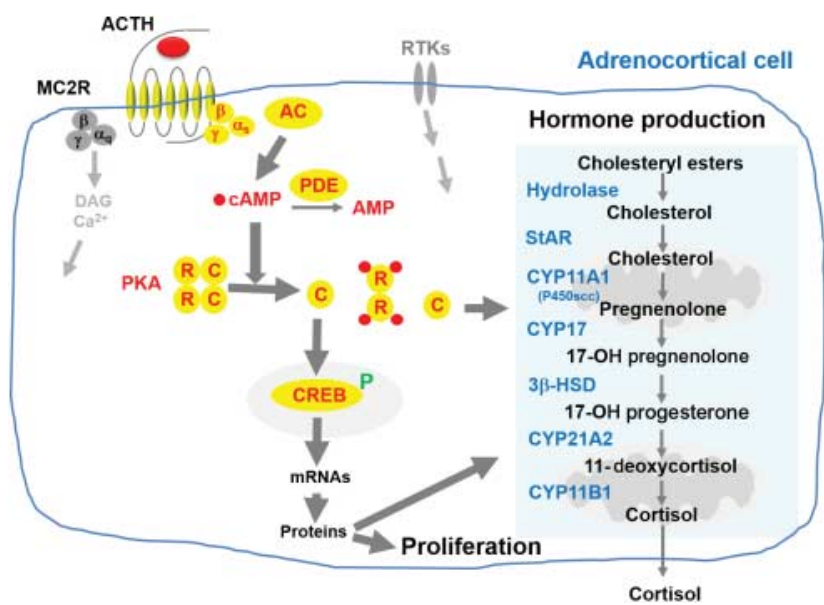

\section{Figure 1}

The CAMP/PKA signaling pathway in adrenocortical cells. An increase in CAMP levels and the subsequent activation of PKA stimulate both cortisol production and cell replication. $\mathrm{MC2R}$, melanocortin 2 receptor; $A C$, adenylyl cyclase; PDE, phosphodiesterase; PKA, protein kinase $A ; R$, regulatory subunit of PKA; $C$, catalytic subunit of PKA.

inactivating mutations in the genes coding for two phosphodiesterases (PDE8 and PDE11A), which are responsible for the degradation of cAMP, have been shown to predispose to the development of adrenal hyperplasia $(45,46,47,48)$.

Considering the importance of impaired cAMP/PKA signaling in the development of adrenal hyperplasia associated with cortisol hypersecretion, the study of those alterations has been extended to sporadic adrenocortical tumors as well. Indeed, somatic mutations of GNAS (9, 10, 11), PRKAR1A (49), and PDE8B (47) have been found also in sporadic adrenocortical adenomas associated with cortisol hypersecretion. However, those mutations were able to explain only a small number of cases, and the molecular pathogenesis of these tumors, which represent a relevant cause of Cushing's syndrome, remained until recently largely obscure.

\section{PRKACA mutations}

With the aim of identifying the underlying genetic alterations, our groups recently performed whole exome sequencing in sporadic cortisol-secreting adrenocortical adenomas (8). We found two mutations in the gene coding for the C $\alpha$ subunit of PKA (PRKACA) in about 30\% of the tumors (8). All mutated adenomas were associated with overt Cushing's syndrome (8). The more frequent of the two mutations (p.Leu206Arg) resulted in the substitution of a leucine residue at position 206 with arginine; the second mutation (Leu199_Cys200insTrp) caused insertion of a tryptophan residue between the amino acid 199 and 200 (8). Functional experiments revealed that both mutations caused constitutive PKA activation (i.e., PKA activation in the absence of cAMP), thus providing a molecular explanation for the development of cortisol-secreting adrenocortical adenomas (8). These findings were confirmed by three independent studies by other groups, as summarized in Table $2(9,10,11)$. In a subsequent targeted analysis of the PRKACA gene, we have identified two novel mutations (p.Cys200_Gly201insVal in three adenomas and p.Ser213Arg + p.Leu212_Lys214 insIle-Ile-Leu-Arg in one) (50).

All the mutations found in cortisol-secreting adrenocortical adenomas involve amino acids that reside on the surface of the $C$ subunit and are located at the interface with the $\mathrm{R}$ subunit (8). By analyzing the solved X-ray crystal structure of the mouse RII $\beta$-C $\alpha$-holoenzyme (37), we predicted that both originally identified mutations might interfere with the association with the $\mathrm{R}$ subunit, thus rendering the $C \alpha$ subunit constitutively active $(8,50,51)$.

Indeed, Leu206 is part of the active site cleft of the C $\alpha$ subunit and participates in forming a hydrophobic pocket $(8,51)$. This hydrophobic pocket is responsible for substrate binding and recognition as well as for the interaction with the inhibitory sequence of the R subunit. Therefore, we predicted that the substitution of Leu206 with a bulky and positively charged amino acid such as arginine would lead to steric hindrance between the side chain of this amino acid and residues Val115 and Tyr228 of the regulatory subunit $(8,51)$ (Fig. 2). This prediction has been well confirmed by a recent X-ray structure of the Leu206Arg mutant (52).

Similarly, residues Leu199 and Cys200 are located next to Thr198, which is part of the so-called 'activation loop' and is phosphorylated during the synthesis of the $\mathrm{C} \alpha$ subunit $(8,34,51)$. This region of the $\mathrm{C}$ subunit is oriented parallel to the inhibitory sequence of the $\mathrm{R}$ subunit.

Table 2 Summary of PRKACA somatic mutations identified by next generation sequencing in patients with hypercortisolism.

\begin{tabular}{|c|c|c|c|c|}
\hline \multirow{2}{*}{$\begin{array}{l}\text { Clinical phenotype } \\
(n(\%))\end{array}$} & \multicolumn{4}{|c|}{ Reporting studies } \\
\hline & (8) & (9) & (10) & (11) \\
\hline Cushing's syndrome & $22(37 \%)$ & $57(66 \%)$ & $13(35 \%)$ & $34(52 \%)$ \\
\hline $\begin{array}{l}\text { Subclinical } \\
\text { hypercortisolism }\end{array}$ & $0(0 \%)$ & $0(0 \%)$ & $3(11 \%)$ & $1(11 \%)$ \\
\hline
\end{tabular}




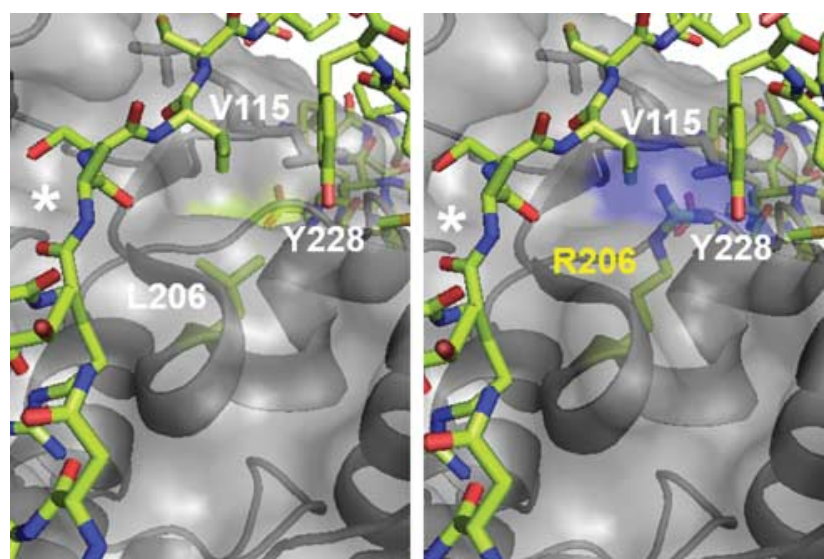

Figure 2

PRKACA mutations identified in cortisol-secreting adrenocortical adenomas interfere with the association between the $C$ and $R$ subunits of PKA. Shown are zoomed-in views of the interface between the $R$ and $C$ subunits based on the structure of the mouse full-length tetrameric RII $\beta(2): C \alpha(2)$ holoenzyme (Protein Data Bank entry 3TNP). Left, WT. Right, predicted structure of the Leu206Arg mutant. Substitution of Leu206 with a bulky and positively charged Arg residue is predicted to result in steric hindrance with the inhibitory sequence $\left(^{*}\right)$ of the $R$ subunit and thus to interfere with the formation of a stable holoenzyme.

Importantly, residues Gly201 and Leu199 are involved in main-chain hydrogen bonding interactions with residues Val115 and Ala117 of the R subunit. Thus, we predicted that an insertion of an additional amino acid at this position might also interfere with the interaction between the $\mathrm{R}$ and $\mathrm{C}$ subunits $(8,51)$.

Finally, although the two subsequently identified mutations do not affect amino acids that directly interact with the $\mathrm{R}$ subunit, it is likely that they might also indirectly interfere with the formation of a stable PKA holoenzyme. The first of these mutations (p.Cys200_ Gly201insVal) involves a region that is oriented in parallel to the inhibitory loop of the $\mathrm{R}$ subunit. The insertion of a valine residue at this position likely results in a bulging out of this area, which might hamper the binding of the $\mathrm{R}$ subunit (50). Similarly, Leu212 is located on the surface of the $\mathrm{C} \alpha$ subunit in a region that protrudes like a 'tip' into the $\mathrm{R}$ subunit. The insertion of several residues at this position as in the case of the second mutation (p.Ser213Arg + p.Leu212_Lys214insIle-IleLeu-Arg) likely leads to an enlargement of this tip, thus also possibly impairing the association between $\mathrm{C}$ and R subunits (50).

\section{Mechanism of PKA activation by PRKACA mutations}

Although several studies have found activating PRKACA mutations - above all the Leu206Arg variant - with a similarly high frequency in cortisol-secreting adrenocortical adenomas, different mechanisms of action have been hypothesized for these mutations $(8,9,10,11)$.

Thus, we have performed a detailed functional characterization of both PRKACA mutations (p.Leu206Arg and Leu199_Cys200insTrp) identified in our initial study (51). In vitro experiments, including co-immunoprecipation assays, chromatography, and real-time fluorescence resonance energy transfer (FRET) measurements, revealed that both mutations largely abolished the association with the R subunits. This was associated with high PKA activity irrespective of the cAMP concentration. In spite of this, the maximal PKA activity of both mutants did not differ from that of the WT $\mathrm{C} \alpha$ subunit. Importantly, by performing FRET experiments in living cells transfected with fluorescently labeled $\mathrm{C}$ and $\mathrm{R}$ subunits, we could demonstrate that both mutations were interfering with the formation of a stable PKA holoenzyme and caused loss of regulation by cAMP also in intact cells (51). These findings provide a mechanistic explanation for the constitutive activation of PKA caused by PRKACA mutations, and thus for the development of cortisolsecreting adrenocortical adenomas in the presence of these mutations.

\section{Genotype-phenotype correlation and interrelation between subclinical hypercortisolism and overt Cushing's syndrome}

Notably, based on the patient cohorts published to date, the presence of PRKACA mutations is clearly associated with a clinical phenotype of overt Cushing's syndrome $(8,9,10,11)$. Moreover, even in the subgroup of patients with Cushing's syndrome, carriers of PRKACA mutations were found to be affected by a more severe endocrine phenotype with higher cortisol secretion at midnight, following dexamethasone suppression or in $24 \mathrm{~h}$ urinary collections (8). In contrast although PRKACA mutations in adrenal adenomas associated with subclinical hypercortisolism cannot be excluded, they seem to be extremely rare.

Studies investigating the natural history of subclinical hypercortisolism published in the last 16 years provide 
Table 3 Overview of long-term follow-up studies reporting the rate of conversion from subclinical to clinical hypercortisolism.

\begin{tabular}{|c|c|c|c|c|}
\hline Reference & $\begin{array}{c}\text { Year of } \\
\text { publication }\end{array}$ & $\begin{array}{c}\text { Patients } \\
\text { with incident- } \\
\text { alomas }(n)\end{array}$ & $\begin{array}{l}\text { Time of } \\
\text { follow-up } \\
\text { (months) }\end{array}$ & $\begin{array}{c}\text { Progression } \\
\text { to overt } \\
\text { Cushing's } \\
\text { syndrome } \\
(n(\%))\end{array}$ \\
\hline (53) & 1998 & 53 & 12 & $0(0)$ \\
\hline (54) & 2001 & 53 & 24 & $0(0)$ \\
\hline (55) & 2002 & 130 & 23.5 & $4(3)$ \\
\hline (56) & 2002 & 64 & 25.5 & $0(0)$ \\
\hline (57) & 2009 & 51 & 51.6 & $3(6)$ \\
\hline (58) & 2009 & 77 & 62.7 & $2(3)$ \\
\hline (30) & 2014 & 206 & 82.5 & $0(0)$ \\
\hline (31) & 2014 & 198 & 90 & $0(0)$ \\
\hline
\end{tabular}

evidence of a low conversion rate toward clinically evident Cushing's syndrome. A summary of the main studies analyzing the natural history of subclinical hypercortisolism and its evolution toward overt Cushing's syndrome is provided in Table 3 . This concept raises the hypothesis that the clinical correlates observed in those patients can be mainly related to the time of exposure to mild hypercortisolism. Although those results could be biased by the variability in the clinical recognition of the features of the syndrome among different physicians, it is clear that subclinical hypercortisolism has a slow evolution in terms of cortisol hypersecretion.

Taken together, these clinical observations together with recent findings on the molecular fingerprint of adrenal adenomas support the hypothesis that subclinical hypercortisolism and overt Cushing's syndrome associated with adrenocortical adenomas could in fact represent two distinct pathological entities. It is tempting to speculate that genetic alterations directly causing cortisol hypersecretion - such as PRKACA mutations - result in a severe phenotype, thus leading to timely clinical recognition and tumor removal. In contrast, genetic - or epigenetic - events that lead to mild hormonal excess are found only incidentally or after prolonged clinical courses and only rarely acquire secondary hits that result in overt clinical symptoms.

\section{Conclusion}

The recent application of high-throughput genetic analyses is unraveling the molecular pathogenesis of sporadic cortisol-secreting adrenocortical adenomas, which was until recently largely obscure. Recent studies identified PRKACA mutations as major genetic alterations responsible for the development of these tumors. These data confirm the key role of the cAMP/PKA signaling pathway in stimulating both the function and the proliferation of adrenocortical cells. They provide insights into the development of adrenal hormonal autonomy and may provide the basis for novel approaches to the diagnosis and therapy of adrenal Cushing's syndrome.

\section{Declaration of interest}

The authors declare that there is no conflict of interest that could be perceived as prejudicing the impartiality of this review.

\section{Funding}

This study was supported by the IZKF Würzburg (grant number B-281 to D Calebiro), the Deutsche Forschungsgemeinschaft (grant number CA 1014/1-1 to D Calebiro), and the ERA-NET 'E-Rare' (grant number 01GM1407B to F Beuschlein and D Calebiro). This project was also funded by the German Federal Ministry of Education and research, Leading-Edge Cluster m4 (to F Beuschlein).

\section{Acknowledgements}

This paper forms part of a special issue of European Journal of Endocrinology on Cushing's syndrome. This article is adapted from work presented at the IMPROCUSH-1: Improving Outcome of Cushing's Syndrome symposium, 12-14 October 2014. The meeting was supported by the European Science Foundation, Deutsche Forschungsgemeinschaft, Carl Friedrich von Siemens Stiftung, European Neuroendocrine Association and the Deutsche Gesellschaft für Endokrinologie. The opinions or views expressed in this special issue are those of the authors, and do not necessarily reflect the opinions or recommendations of the European Science Foundation, Deutsche Forschungsgemeinschaft, Carl Friedrich von Siemens Stiftung, European Neuroendocrine Association and the Deutsche Gesellschaft fur Endokrinologie.

\section{References}

1 Bossis I \& Stratakis CA. Minireview: PRKAR1A: normal and abnormal functions. Endocrinology 2004145 5452-5458. (doi:10.1210/en.2004-0900)

2 Rosenberg D, Groussin L, Jullian E, Perlemoine K, Bertagna X \& Bertherat J. Role of the PKA-regulated transcription factor CREB in development and tumorigenesis of endocrine tissues. Annals of the New York Academy of Sciences 2002968 65-74. (doi:10.1111/j.1749-6632. 2002.tb04327.x)

3 Perez-Nanclares G, Velayos T, Vela A, Muñoz-Torres M \& Castaño L. Pseudohypoparathyroidism type Ib associated with novel duplications in the GNAS locus. PLOS ONE 201510 e0117691. (doi:10.1371/journal. pone.0117691)

4 Persani L, Calebiro D, Cordella D, Weber G, Gelmini G, Libri D, de Filippis $\mathrm{T} \&$ B Bonomi M. Genetics and phenomics of hypothyroidism due to TSH resistance. Molecular and Cellular Endocrinology 2010322 72-82. (doi:10.1016/j.mce.2010.01.008)

5 Lania AG, Mantovani G \& Spada A. Mechanisms of disease: mutations of $\mathrm{G}$ proteins and $\mathrm{G}$-protein-coupled receptors in endocrine diseases. Nature Clinical Practice. Endocrinology \& Metabolism 20062 681-693. (doi:10.1038/ncpendmet0324) 
6 Vassart G \& Costagliola S. G protein-coupled receptors: mutations and endocrine diseases. Nature Reviews. Endocrinology 20117 362-372. (doi:10.1038/nrendo.2011.20)

7 O'Hayre M, Vazquez-Prado J, Kufareva I, Stawiski EW, Handel TM, Seshagiri S \& Gutkind JS. The emerging mutational landscape of G proteins and G-protein-coupled receptors in cancer. Nature Reviews. Cancer 201313 412-424. (doi:10.1038/nrc3521)

8 Beuschlein F, Fassnacht M, Assié G, Calebiro D, Stratakis CA, Osswald A, Ronchi CL, Wieland T, Sbiera S, Faucz FR et al. Constitutive activation of PKA catalytic subunit in adrenal Cushing's syndrome. New England Journal of Medicine 2014370 1019-1028. (doi:10.1056/ NEJMoa1310359)

9 Cao Y, He M, Gao Z, Peng Y, Li Y, Li L, Zhou W, Li X, Zhong X, Lei Y et al. Activating hotspot L205R mutation in PRKACA and adrenal Cushing's syndrome. Science 2014344 913-917. (doi:10.1126/science.1249480)

10 Goh G, Scholl UI, Healy JM, Choi M, Prasad ML, Nelson-Williams C, Kunstman JW, Korah R, Suttorp A-C, Dietrich D et al. Recurrent activating mutation in PRKACA in cortisol-producing adrenal tumors. Nature Genetics 201446 613-617. (doi:10.1038/ng.2956)

11 Sato Y, Maekawa S, Ishii R, Sanada M, Morikawa T, Shiraishi Y, Yoshida K, Nagata Y, Sato-Otsubo A, Yoshizato T et al. Recurrent somatic mutations underlie corticotropin-independent Cushing's syndrome. Science 2014344 917-920. (doi:10.1126/science.1252328)

12 Stratakis CA. Cushing syndrome caused by adrenocortical tumors and hyperplasias (corticotropin-independent Cushing syndrome). Endocrine Development 200813 117-132. (doi:10.1159/000134829)

13 Nieman LK, Biller BM, Findling JW, Newell-Price J, Savage MO, Stewart PM \& Montori VM. The diagnosis of Cushing's syndrome: an Endocrine Society Clinical Practice Guideline. Journal of Clinical Endocrinology and Metabolism 200893 1526-1540. (doi:10.1210/jc.2008-0125)

14 Magiakou MA, Smyrnaki P \& Chrousos GP. Hypertension in Cushing's syndrome. Best Practice \& Research. Clinical Endocrinology \& Metabolism 200620 467-482. (doi:10.1016/j.beem.2006.07.006)

15 Arnaldi G, Mancini T, Polenta B \& Boscaro M. Cardiovascular risk in Cushing's syndrome. Pituitary 20047 253-256. (doi:10.1007/ s11102-005-1172-7)

16 Zacharieva S, Orbetzova M, Stoynev A, Shigarminova R, Yaneva M, Kalinov K, Nachev E \& Elenkova A. Circadian blood pressure profile in patients with Cushing's syndrome before and after treatment. Journal of Endocrinological Investigation 200427 924-930. (doi:10.1007/ BF03347534)

17 Trementino L, Arnaldi G, Appolloni G, Daidone V, Scaroni C, Casonato A \& Boscaro M. Coagulopathy in Cushing's syndrome. Neuroendocrinology 201092 (Suppl 1) 55-59. (doi:10.1159/000314349)

18 Lindholm J, Juul S, Jorgensen JO, Astrup J, Bjerre P, Feldt-Rasmussen U, Hagen C, Jorgensen J, Kosteljanetz M, Kristensen L et al. Incidence and late prognosis of Cushing's syndrome: a population-based study. Journal of Clinical Endocrinology and Metabolism 200186 117-123. (doi:10.1210/jcem.86.1.7093)

19 Arnaldi G, Mancini T, Tirabassi G, Trementino L \& Boscaro M. Advances in the epidemiology, pathogenesis, and management of Cushing's syndrome complications. Journal of Endocrinological Investigation 201235 434-448. (doi:10.1007/BF03345431)

20 Plotz CM, Knowlton AI \& Ragan C. The natural history of Cushing's syndrome. American Journal of Medicine 195213 597-614. (doi:10.1016/ 0002-9343(52)90027-2)

21 Colao A, Cozzolino A \& Pivonello R. Quality of life in patients with Cushing's disease: a modern approach. Clinical Endocrinology 201276 776-777. (doi:10.1111/j.1365-2265.2012.04344.x)

22 Chiodini I. Clinical review: diagnosis and treatment of subclinical hypercortisolism. Journal of Clinical Endocrinology and Metabolism 2011 96 1223-1236. (doi:10.1210/jc.2010-2722)

23 Bovio S, Cataldi A, Reimondo G, Sperone P, Novello S, Berruti A, Borasio P, Fava C, Dogliotti L, Scagliotti GV et al. Prevalence of adrenal incidentaloma in a contemporary computerized tomography series. Journal of Endocrinological Investigation 2006 29 298-302. (doi:10.1007/BF03344099)
24 Chiodini I, Guglielmi G, Battista C, Carnevale V, Torlontano M, Cammisa M, Trischitta V \& Scillitani A. Spinal volumetric bone mineral density and vertebral fractures in female patients with adrenal incidentalomas: the effects of subclinical hypercortisolism and gonadal status. Journal of Clinical Endocrinology and Metabolism 200489 2237-2241. (doi:10.1210/jc.2003-031413)

25 Tauchmanova L, Pivonello R, De Martino MC, Rusciano A, De Leo M, Ruosi C, Mainolfi C, Lombardi G, Salvatore M \& Colao A. Effects of sex steroids on bone in women with subclinical or overt endogenous hypercortisolism. European Journal of Endocrinology 2007157 359-366. (doi:10.1530/EJE-07-0137)

26 Chiodini I, Viti R, Coletti F, Guglielmi G, Battista C, Ermetici F, Morelli V, Salcuni A, Carnevale V, Urbano F et al. Eugonadal male patients with adrenal incidentalomas and subclinical hypercortisolism have increased rate of vertebral fractures. Clinical Endocrinology 200970 208-213. (doi:10.1111/j.1365-2265.2008.03310.x)

27 Chiodini I, Morelli V, Masserini B, Salcuni AS, Eller-Vainicher C, Viti R, Coletti F, Guglielmi G, Battista C, Carnevale V et al. Bone mineral density, prevalence of vertebral fractures, and bone quality in patients with adrenal incidentalomas with and without subclinical hypercortisolism: an Italian multicenter study. Journal of Clinical Endocrinology and Metabolism 200994 3207-3214. (doi:10.1210/jc.2009-0468)

28 Morelli V, Eller-Vainicher C, Salcuni AS, Coletti F, Iorio L, Muscogiuri G, Della Casa S, Arosio M, Ambrosi B, Beck-Peccoz P et al. Risk of new vertebral fractures in patients with adrenal incidentaloma with and without subclinical hypercortisolism: a multicenter longitudinal study. Journal of Bone and Mineral Research 201126 1816-1821. (doi:10.1002/jbmr.398)

29 Di Dalmazi G, Vicennati V, Rinaldi E, Morselli-Labate AM, Giampalma E, Mosconi C, Pagotto U \& Pasquali R. Progressively increased patterns of subclinical cortisol hypersecretion in adrenal incidentalomas differently predict major metabolic and cardiovascular outcomes: a large cross-sectional study. European Journal of Endocrinology 2012166 669-677. (doi:10.1530/EJE-11-1039)

30 Morelli V, Reimondo G, Giordano R, Della Casa S, Policola C, Palmieri S, Salcuni AS, Dolci A, Mendola M, Arosio M et al. Long-term follow-up in adrenal incidentalomas: an Italian multicenter study. Journal of Clinical Endocrinology and Metabolism 201499 827-834. (doi:10.1210/jc.2013-3527)

31 Di Dalmazi G, Vicennati V, Garelli S, Casadio E, Rinaldi E, Giampalma E, Mosconi C, Golfieri R, Paccapelo A, Pagotto U et al. Cardiovascular events and mortality in patients with adrenal incidentalomas that are either non-secreting or associated with intermediate phenotype or subclinical Cushing's syndrome: a 15-year retrospective study. Lancet. Diabetes \& Endocrinology 20142 396-405. (doi:10.1016/ S2213-8587(13)70211-0)

32 Debono M, Bradburn M, Bull M, Harrison B, Ross RJ \& Newell-Price J. Cortisol as a marker for increased mortality in patients with incidental adrenocortical adenomas. Journal of Clinical Endocrinology and Metabolism 201499 4462-4470. (doi:10.1210/jc.2014-3007)

33 Chin K-V, Yang W-L, Ravatn R, Kita T, Reitman E, Vettori D, Cvijic ME, Shin M \& Iacono L. Reinventing the wheel of cyclic AMP. Annals of the New York Academy of Sciences 2002968 49-64. (doi:10.1111/j.17496632.2002.tb04326.x)

34 Taylor SS, Ilouz R, Zhang P \& Kornev AP. Assembly of allosteric macromolecular switches: lessons from PKA. Nature Reviews. Molecular Cell Biology 201213 646-658. (doi:10.1038/nrm3432)

35 Diskar M, Zenn H-M, Kaupisch A, Kaufholz M, Brockmeyer S, Sohmen D, Berrera M, Zaccolo M, Boshart M, Herberg FW et al. Regulation of cAMP-dependent protein kinases: the human protein kinase $\mathrm{X}$ (PrKX) reveals the role of the catalytic subunit $\alpha \mathrm{H}-\alpha \mathrm{I}$ loop. Journal of Biological Chemistry 2010285 35910-35918. (doi:10.1074/jbc. M110.155150)

36 Taskén K, Skålhegg BS, Solberg R, Andersson KB, Taylor SS, Lea T, Blomhoff HK, Jahnsen T \& Hansson V. Novel isozymes of cAMPdependent protein kinase exist in human cells due to formation of 
RI $\alpha$-RI $\beta$ heterodimeric complexes. Journal of Biological Chemistry 1993 268 21276-21283.

37 Kim C, Xuong N-H \& Taylor SS. Crystal structure of a complex between the catalytic and regulatory (RI $\alpha$ ) subunits of PKA. Science $2005 \mathbf{3 0 7}$ 690-696. (doi:10.1126/science.1104607)

38 Gallo-Payet N \& Payet MD. Mechanism of action of ACTH: beyond cAMP. Microscopy Research and Technique 200361 275-287. (doi:10. 1002/jemt.10337)

39 Sewer M \& Waterman M. cAMP-dependent transcription of steroidogenic genes in the human adrenal cortex requires a dual-specificity phosphatase in addition to protein kinase A. Journal of Molecular Endocrinology 200229 163-174. (doi:10.1677/jme.0.0290163)

40 Almeida MQ \& Stratakis CA. How does cAMP/protein kinase A signaling lead to tumors in the adrenal cortex and other tissues? Molecular and Cellular Endocrinology 2011336 162-168. (doi:10.1016/ j.mce.2010.11.018)

41 Weinstein LS, Shenker A, Gejman PV, Merino MJ, Friedman E \& Spiegel AM. Activating mutations of the stimulatory G protein in the McCune-Albright syndrome. New England Journal of Medicine 1991325 1688-1695. (doi:10.1056/NEJM199112123252403)

42 Bertherat J, Groussin L \& Bertagna X. Mechanisms of disease: adrenocortical tumors - molecular advances and clinical perspectives. Nature Clinical Practice. Endocrinology \& Metabolism 20062 632-641. (doi:10.1038/ncpendmet0321)

43 Kirschner LS, Carney JA, Pack SD, Taymans SE, Giatzakis C, Cho YS, Cho-Chung YS \& Stratakis CA. Mutations of the gene encoding the protein kinase A type I-[ $\alpha]$ regulatory subunit in patients with the Carney complex. Nature Genetics 200026 89-92. (doi:10.1038/79238)

44 Bertherat J, Horvath A, Groussin L, Grabar S, Boikos S, Cazabat L, Libe R, René-Corail F, Stergiopoulos S, Bourdeau I et al. Mutations in regulatory subunit type $1 \mathrm{~A}$ of cyclic adenosine $5^{\prime}$-monophosphate-dependent protein kinase (PRKAR1A): phenotype analysis in 353 patients and 80 different genotypes. Journal of Clinical Endocrinology and Metabolism 200994 2085-2091. (doi:10.1210/jc.2008-2333)

45 Horvath A, Boikos S, Giatzakis C, Robinson-White A, Groussin L, Griffin KJ, Stein E, Levine E, Delimpasi G, Hsiao HP et al. A genome-wide scan identifies mutations in the gene encoding phosphodiesterase 11A4 (PDE11A) in individuals with adrenocortical hyperplasia. Nature Genetics 200638 794-800. (doi:10.1038/ng1809)

46 Horvath A, Giatzakis C, Robinson-White A, Boikos S, Levine E, Griffin K, Stein E, Kamvissi V, Soni P, Bossis I et al. Adrenal hyperplasia and adenomas are associated with inhibition of phosphodiesterase $11 \mathrm{~A}$ in carriers of PDE11A sequence variants that are frequent in the population. Cancer Research 200666 11571-11575. (doi:10.1158/00085472.CAN-06-2914)

47 Rothenbuhler A, Horvath A, Libé R, Faucz FR, Fratticci A, Sanson MLR, Vezzosi D, Azevedo M, Levi I, Almeida MQ et al. Identification of novel genetic variants in phosphodiesterase 8B (PDE8B), a cAMP specific phosphodiesterase highly expressed in the adrenal cortex, in a cohort of patients with adrenal tumors. Clinical Endocrinology 201277 195-199. (doi:10.1111/j.1365-2265.2012.04366.x)

48 Tsai L-CL, Shimizu-Albergine M \& Beavo JA. The high-affinity cAMPspecific phosphodiesterase $8 \mathrm{~B}$ controls steroidogenesis in the mouse adrenal gland. Molecular Pharmacology 201179 639-648. (doi:10.1124/ mol.110.069104)

49 Bertherat J, Groussin L, Sandrini F, Matyakhina L, Bei T, Stergiopoulos S, Papageorgiou T, Bourdeau I, Kirschner LS, VincentDejean C et al. Molecular and functional analysis of PRKAR1A and its locus (17q22-24) in sporadic adrenocortical tumors: 17q losses, somatic mutations, and protein kinase A expression and activity. Cancer Research 200363 5308-5319.

50 Di Dalmazi G, Kisker C, Calebiro D, Mannelli M, Canu L, Arnaldi G, Quinkler M, Rayes N, Tabarin A, Laure Jullié M et al. Novel somatic mutations in the catalytic subunit of the protein kinase A as a cause of adrenal Cushing's syndrome: a European multicentric study. Journal of Clinical Endocrinology and Metabolism 201499 E2093-E2100. (doi:10.1210/jc.2014-2152)

51 Calebiro D, Hannawacker A, Lyga S, Bathon K, Zabel U, Ronchi C, Beuschlein F, Reincke M, Lorenz K, Allolio B et al. PKA catalytic subunit mutations in adrenocortical Cushing's adenoma impair association with the regulatory subunit. Nature Communications 201455680. (doi:10.1038/ncomms6680)

52 Cheung J, Ginter C, Cassidy M, Franklin MC, Rudolph MJ, Robine N, Darnell RB \& Hendrickson WA. Structural insights into mis-regulation of protein kinase A in human tumors. PNAS 2015112 1374-1379. (doi:10.1073/pnas.1424206112)

53 Terzolo M, Osella G, Alì A, Borretta G, Cesario F, Paccotti P \& Angeli A. Subclinical Cushing's syndrome in adrenal incidentaloma. Clinical Endocrinology 199848 89-97. (doi:10.1046/j.1365-2265.1998.00357.x)

54 Grossrubatscher E, Vignati F, Possa M \& Lohi P. The natural history of incidentally discovered adrenocortical adenomas: a retrospective evaluation. Journal of Endocrinological Investigation 200124 846-855. (doi:10.1007/BF03343941)

55 Barzon L, Fallo F, Sonino N \& Boscaro M. Development of overt Cushing's syndrome in patients with adrenal incidentaloma. European Journal of Endocrinology 2002146 61-66. (doi:10.1530/eje.0.1460061)

56 Libè R, Dall'Asta C, Barbetta L, Baccarelli A, Beck-Peccoz P \& Ambrosi B. Long-term follow-up study of patients with adrenal incidentalomas. European Journal of Endocrinology 2002147 489-494.

57 Fagour C, Bardet S, Rohmer V, Arimone Y, Lecomte P, Valli N \& Tabarin A. Usefulness of adrenal scintigraphy in the follow-up of adrenocortical incidentalomas: a prospective multicenter study. European Journal of Endocrinology 2009160 257-264. (doi:10.1530/ EJE-08-0299)

58 Vassilatou E, Vryonidou A, Michalopoulou S, Manolis J, Caratzas J, Phenekos C \& Tzavara I. Hormonal activity of adrenal incidentalomas: results from a long-term follow-up study. Clinical Endocrinology 200970 674-679. (doi:10.1111/j.1365-2265.2008.03492.x)
Received 1 April 2015

Revised version received 18 June 2015

Accepted 23 June 2015 